\title{
Esophageal bypass could improve the quality of life of patients with far-advanced esophageal carcinoma associated with complicated organ disease
}

\author{
Tadahiro Nozoe, Shuhei Ito, Takefumi Ohga, Takahiro Ezaki
}

\begin{abstract}
Introduction: Dysphagia due to passage disturbance is the most distressing symptom of patients with far-advanced esophageal carcinoma that cannot be treated by curative resection. Case Report: We experienced a 74-year-old patient with far-advanced esophageal carcinoma associated with severe interstitial pneumonia for whom bypass surgery was able to improve the quality of life. While he was able to enjoy eating for more than a year, he died of respiratory failure due to deterioration of the interstitial pneumonia 14 months after the surgical treatment. Conclusion: Bypass surgery can be considered one of the therapeutic options for patients with far-advanced esophageal carcinoma who suffer from passage disturbance.
\end{abstract}

Keywords: Bypass surgery, Esophageal carcinoma, Food intake

Tadahiro Nozoe ${ }^{1}$, Shuhei Ito ${ }^{1}$, Takefumi Ohga ${ }^{1}$, Takahiro Ezaki $^{1}$

Affiliation: ${ }^{1}$ Department of Surgery, Fukuoka Higashi Medical Center, 1-1-1, Chidori, Koga, Japan.

Corresponding Author: Tadahiro Nozoe, MD, Department of Surgery, Fukuoka Higashi Medical Center, 1-1-1, Chidori, Koga, 811-3195, Japan; Email: paper7777@yahoo.co.jp, nozoet@fukuokae2.hosp.go.jp

Received: 09 March 2015

Accepted: 25 May 2018

Published: 10 July 2018

\section{How to cite this article}

Nozoe T, Ito S, Ohga T, Ezaki T. Esophageal bypass could improve the quality of life of patients with faradvanced esophageal carcinoma associated with complicated organ disease. Int J Case Rep Images 2018;9:100934Z01TN2018.

Article ID: 100934Zo1TN2018

$* * * * * * * * *$

doi: 10.5348/100934Z01TN2018CR

\section{INTRODUCTION}

Esophageal carcinoma is a tumor that has a dismal prognosis [1]. There are two main clinical problems that distress the patients with advanced esophageal carcinoma associated with obstruction of the esophageal lumen. Firstly, the prognosis of patients with such an advanced tumor is likely quite unfavorable. Secondly, the patients suffer from severe passage disturbance due to the obstructing tumor.

Therefore, the greatest blessing for patients with advanced esophageal carcinoma that cannot be cured by curative resection might be to provide the chance for oral food intake.

For patients with far-advanced esophageal carcinoma with severe passage disturbance for which curative resection would not be possible, conservative treatments, such as chemo-radiotherapy and/or stenting, have generally been selected as the first choice therapeutic option [2]. On the other hand, bypass surgery for such patients has been perceived as a far more invasive treatment with only a small benefit for the patients.

Herein we report the case of a 74-year-old male patient with far-advanced esophageal carcinoma that was not 


\section{EDORIUM Journals}

Int J Case Rep Images 2018;9:100934Z01TN2018.

www.ijcasereportsandimages.com

Nozoe et al. 2

indicated for curative resection and was associated with severe interstitial pneumonia, for whom bypass surgery led to an improvement in oral food intake.

\section{CASE REPORT}

A 74-year-old man, who had been suffering from food passage disturbance for about two months, was referred to our institute.

A laboratory data showed a normal value of hemoglobin (13.9 g/dL), and serum albumin ( $4.4 \mathrm{~g} / \mathrm{dL})$, and a serum elevation of C-reactive protein $(7.9 \mathrm{mg} / \mathrm{dL})$ demonstrating an inflammatory condition. There was no increase in tumor marker SCC antigen $(0.9 \mathrm{ng} / \mathrm{mL})$.

A computed tomography demonstrated the presence of a far-advanced tumor in the middle thoracic esophagus that was likely to invade to the bronchus and an additional finding of severe interstitial pneumonia (Figure 1). The histological diagnosis was moderately differentiated squamous cell carcinoma, and the clinical stage of the tumor was diagnosed as T3NoMo. He was continued an oral corticosteroid for half a year to avoid deterioration of the interstitial pneumonia.

Although the patient's performance status was Grade 1 , physical condition showed that he was unlikely to tolerate esophagectomy and digestive reconstruction associated with thoracotomy. However, he said, "I would like to take meal, especially my favorite dish, only once again. This is my last desire." In order to realize his enthusiastic desire, esophageal bypass was planned as the most suitable therapeutic option.

The surgical procedure is depicted in Figure 2. A laparotomy and an esophageal dissection were performed and a gastric tube using the portion of greater curvature fed by a right gastro-epiploic artery was made. After making a collar incision, a cervical-esophagogastrostomy was performed through a retro-sternal route. Digestive reconstruction was completed using a Roux-en-Y method, including an esophago-jejunostomy and a jejuno-jejunostomy.

The patient did not experience any postoperative complications, such as anastomotic leak, and he was able to begin to take a meal 14 days after the surgical procedure and was discharged from the hospital 28 days after operation. While he was able to enjoy taking meals for more than one year, he died of the respiratory failure due to deterioration of the interstitial pneumonia 14 months after the surgical treatment.

\section{DISCUSSION}

The potential benefits and disadvantages of bypass surgery for patients with far-advanced esophageal carcinoma with esophageal obstruction and/or tumor invasion to the surrounding organs to help for oral intake of food have been discussed extensively [2-5].

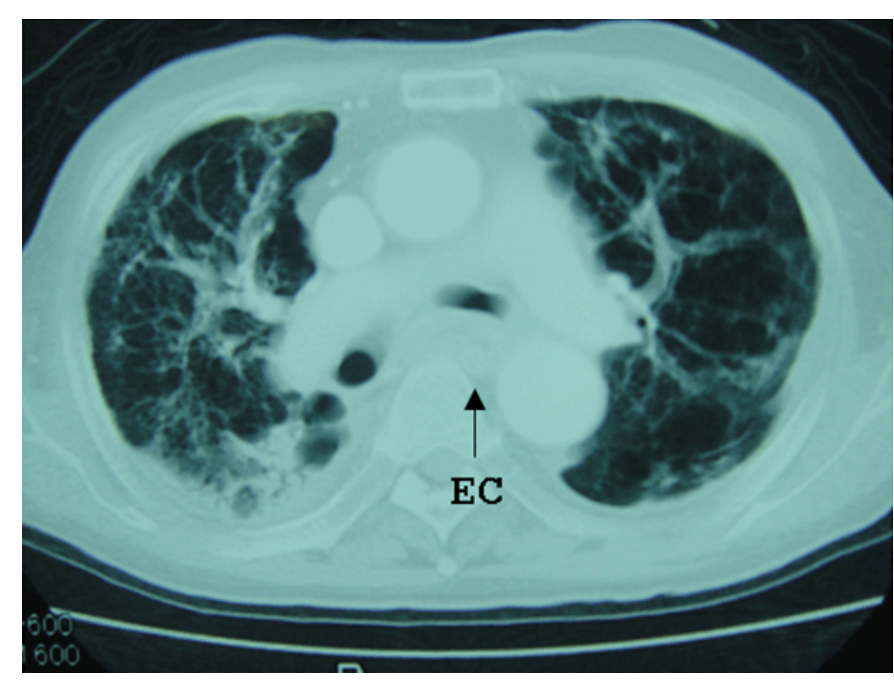

Figure 1: Findings of computed tomography. The right bronchus was compressed by an advanced esophageal tumor in the middle thoracic esophagus. Moreover there was an additional finding of severe interstitial pneumonia.

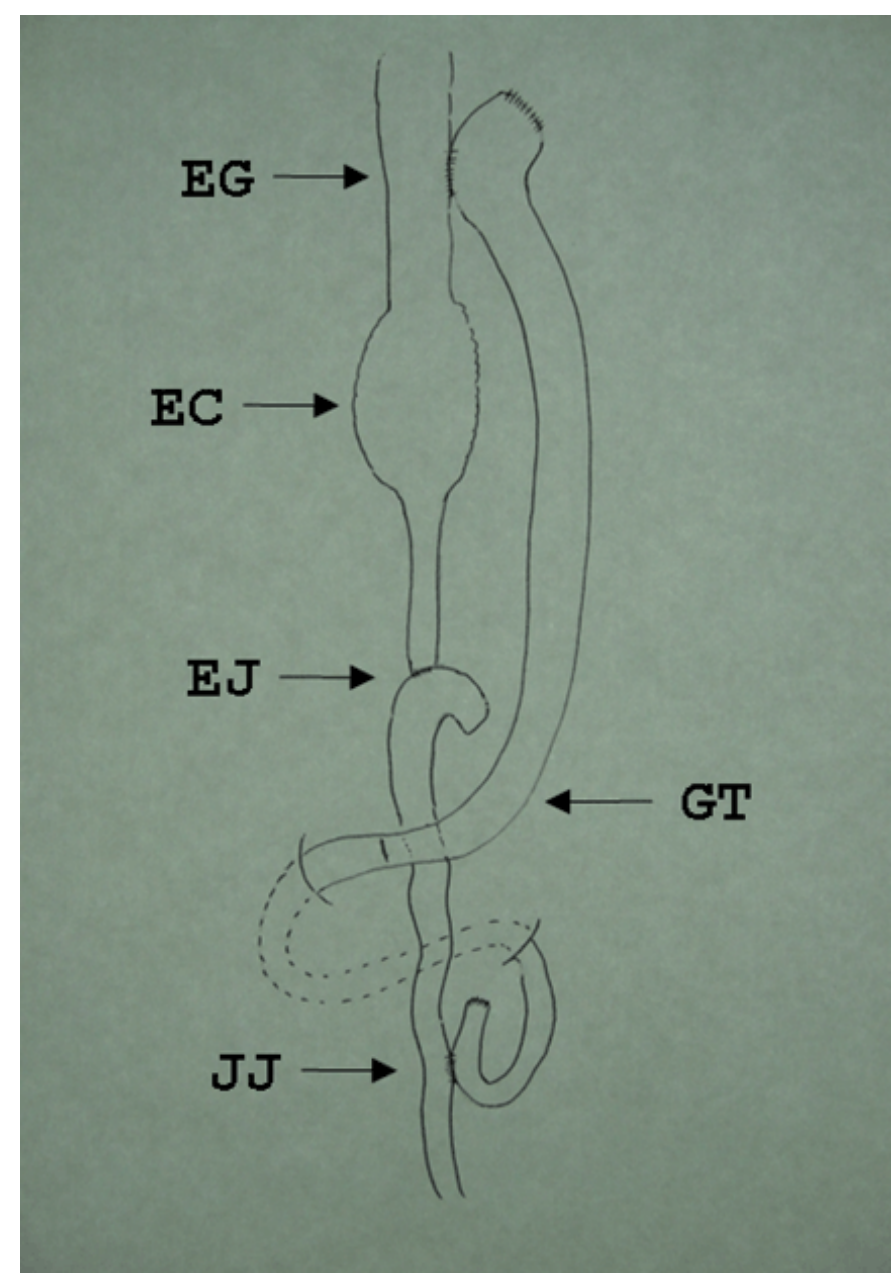

Figure 2: Surgical procedures.

EG: esophago-gastrostomy, EC: esophageal carcinoma, EJ: esophago-jejunostomy, GT: gastric tube, JJ: jejunojejunostomy. 


\section{EDORIUM Journals}

Stent placement, which is generally believed to be less-invasive, might be selected initially for patients with incurable esophageal carcinoma with esophageal obstruction or esophago-bronchial fistula because it has been reported that improvement of oral food intake acquired by the therapy was no different from that of patients treated with bypass surgery [2].

Indeed, according to the therapeutic guidelines for esophageal carcinoma from the Japanese Society for Esophageal Diseases, the recommended treatment for patients with far-advanced carcinoma for whom curative resection would not be possible is chemo-radiotherapy and/or stenting, especially for those patients with severe passage disturbance. However, while the absolute volume of the tumors might be reduced by induction chemoradiotherapy, passage disturbance due to the esophageal stricture cannot be improved by stent insertion and/ or chemoradiotherapy to the degree that physicians would expect [2]. Moreover, esophageal stent insertion occasionally causes life-threatening complications, such as bleeding and esophageal perforation [6-8]. However, our patient was unlikely to be indicated to undergo chemotherapy or chemoradiotherapy because of the coexistence of severe interstitial pneumonia.

In general, bypass surgery has been associated with a high morbidity [2]. The reason for this might be that patients with passage disturbance by esophageal carcinoma are occasionally in a compromised immunonutritional state [9]. In particular, the incidence of anastomotic leaks as the most terrible complication would negate the initial aims of this treatment to achieve oral intake and improve the general condition. While our patient continued to take corticosteroid, which might interfere a wound healing, to avoid the deterioration of interstitial pneumonia, an anastomotic leak was predicted to occur. Fortunately, he did not experience this unfavorable complication.

Yajima et al., [10] investigated the patients' quality of the life with esophageal obstructing carcinoma who had been treated with stent insertion, and showed that the median duration of possible food intake and the median survival were 95 and 108 days, respectively. The survival time of patients with far-advanced esophageal carcinoma who underwent stent insertion after chemoradiotherapy due to insufficient food intake was 91 days [11].

Our patient was able to take meals for one year and survived for 14 months before his physical condition collapsed due to the deterioration of the cachexic condition as a consequence of growth of the tumor, with respiratory failure derived from the interstitial pneumonia. This clinical course appeared to be better compared with that of patients treated with stent insertion therapy with or without preceding chemoradiotherapy that were reported in previous investigations $[10,11]$.

For patients who do not have any complicating disease other than esophageal carcinoma, additional therapeutic options to prevent tumor growth should be considered after improvement of oral food intake and the general condition.

\section{CONCLUSION}

In conclusion, esophageal bypass surgery might be selected as a suitable therapeutic option for patients with far-advanced esophageal carcinoma, who are unable to take food orally, especially those associated with complicated organ diseases. Although surgeons should be cautious and meticulous in determining the indication for bypass surgery, this therapeutic option is considered to contribute to providing the last opportunity and to meet the needs of esophageal carcinoma patients to continue oral food intake.

\section{REFERENCES}

1. Daly JM, Fry WA, Little AG, et al. Esophageal cancer: Rsults of an American college of surgeons patient care evaluation study. J Am Coll Surg 2000 May;190(5):562-72.

2. Aoki T, Osaka Y, Takagi Y, et al. Comparative study of self-expandable metallic stent and bypass surgery for inoperable esophageal cancer. Dis Esophagus 2001;14(3-4):208-11.

3. Chauhan SS, Long JD. Management of tracheoesophageal fistulas in adults. Curr Treat Options Gastroenterol 2004 Feb;7(1):31-40.

4. Alcantara PS, Spencer-Netto FA, Silva-Júnior JF, Soares LA, Pollara WM, Bevilacqua RG. Gastroesophageal isoperistaltic bypass in the palliation of irresectable thoracic esophageal cancer. Int Surg 1997 Jul-Sep;82(3):249-53.

5. Meunier B, Spiliopoulos Y, Stasik C, Lakéhal M, Malledant Y, Launois B. Retrosternal bypass operation for unresectable squamous cell cancer of the esophagus. Ann Thorac Surg 1996 Aug;62(2):373-7.

6. Homs MY, Hansen BE, van Blankenstein $M$, Haringsma J, Kuipers EJ, Siersema PD. Prior radiation and/or chemotherapy has no effect on the outcome of metal stent placement for oesophagogastric carcinoma. Eur J Gastroenterol Hepatol 2004 Feb;16(2):163-70.

7. Yakami M, Mitsumori M, Sai H, Nagata Y, Hiraoka M, Nishimura Y. Development of severe complications caused by stent placement followed by definitive radiation therapy for $\mathrm{T} 4$ esophageal cancer. Int J Clin Oncol 2003 Dec;8(6):395-8.

8. Kinsman KJ, DeGregorio BT, Katon RM, et al. Prior radiation and chemotherapy increase the risk of lifethreatening complications after insertion of metallic stents for esophagogastric malignancy. Gastrointest Endosc 1996 Mar;43(3):196-203.

9. Nozoe T, Kimura Y, Ishida M, Saeki H, Korenaga D, Sugimachi K. Correlation of pre-operative nutritional condition with post-operative complications in surgical treatment for oesophageal carcinoma. Eur J Surg Oncol 2002 Jun;28(4):396-400. 
www.ijcasereportsandimages.com

10. Yajima K, Kanda T, Nakagawa S, et al. Self-expandable metallic stents for palliation of malignant esophageal obstruction: Special reference to quality of life and survival of patients. Dis Esophagus 2004;17(1):71-5.

11. Funami Y, Tokumoto N, Miyauchi H, Kuga K, Sato S. Improvement of oral ingestion in patients with inoperable esophageal cancer treated with radiotherapy, chemotherapy and insertion of a self-expanding nitinol stent. Dis Esophagus 1999;12(4):289-93.

$* * * * * * * * *$

\section{Author Contributions}

Tadahiro Nozoe - Substantial contributions to conception and design, Acquisition of data, Analysis and interpretation of data, Drafting the article, Revising it critically for important intellectual content, Final approval of the version to be published

Shuhei Ito - Substantial contributions to conception and design, Drafting the article, Final approval of the version to be published

Takefumi Ohga - Substantial contributions to conception and design, Drafting the article, Final approval of the version to be published
Takahiro Ezaki - Substantial contributions to conception and design, Drafting the article, Final approval of the version to be published

\section{Guarantor of Submission}

The corresponding author is the guarantor of submission.

\section{Source of Support \\ None}

\section{Consent Statement}

Written informed consent was obtained from the patient for publication of this case report.

\section{Conflict of Interest}

Authors declare no conflict of interest.

\section{Copyright}

(C) 2018 Tadahiro Nozoe et al. This article is distributed under the terms of Creative Commons Attribution License which permits unrestricted use, distribution and reproduction in any medium provided the original author(s) and original publisher are properly credited. Please see the copyright policy on the journal website for more information.
Access full text article on other devices

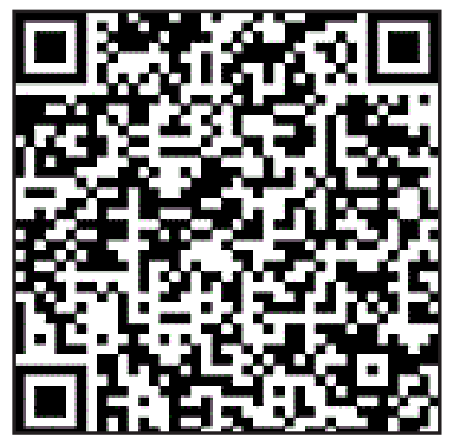

Access PDF of article on other devices

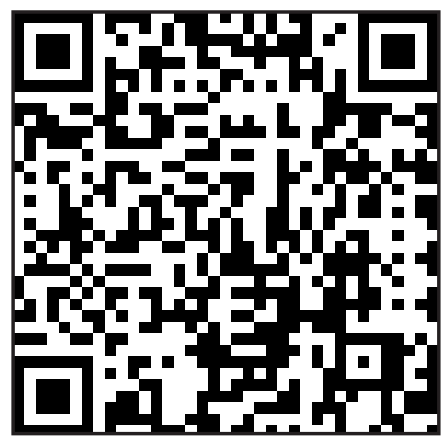

